\title{
Coronary Risk Profile of Young Soldiers with Coronary Heart Disease
}

\author{
Lt Col P Lynch, \\ MRCP, MD, RAMC \\ Cardiac Dept, Queen Elizabeth Military Hospital, Woolwich
}

\begin{abstract}
In a retrospective study of coronary risk factors in young soldiers with coronary heart disease (CHD), designed to explain why junior ranks in the British Army have a higher mortality rate from CHD than comparable British civilians, high prevalence of heavy cigarette smoking was found to be the major discriminant. In general, young men with CHD have higher prevalence of cigarette smoking, and a higher per capita consumption than older men with CHD. They also have higher cholesterol levels, perhaps resulting from more symptomatic cases of familial hypercholesterolaemia in the younger age group. Young affected soldiers are more obese than young affected civilians and smoke more cigarettes ( $24 \%$ smoke 40 or more per day). This may be related to the reduced cost of cigarettes to soldiers in some parts of the world. In the British Army, the expected protective effect of physical fitness is overwhelmed by the deleterious effect of high cigarette consumption.
\end{abstract}

\section{Introduction}

Following the surprising discovery that junior ranks in the British Army have a higher mortality from coronary heart disease (CHD) than comparable British civilians ${ }^{1}$, this paper sets out to examine the conventional coronary risk profile of young soldiers with CHD in an attempt to explain this difference.

\section{Subjects and Method}

The subjects of this paper are 164 British Army males with CHD, under the age of 40 years (mean $34.6 \mathrm{SD}$ three years) diagnosed between 1976 and 1981. The diagnosis was established in 48 cases by coronary angiogram showing luminal obstruction of $70 \%$ or more in at least one coronary artery and in a further 48 cases by detailed autopsy report of severe atheroma in at least one coronary artery. In a further 55 cases the diagnosis was established by a history of crushing retrosternal chest pain lasting at least one hour, associated with deep $Q$ waves on the electrocardiogram (ECG) and a rise in cardiac enzymes to at least three times the upper limit of normality. A further 13 cases with chest pain typical of angina or myocardial infarction were accepted with $Q$ waves on the electrocardiogram and a corrresponding defect on thallium scan (five cases), ST or T wave changes on ECG with a defect on thallium scan (four cases), planar or downsloping ST segment depression on ECG of at least two millimetres on symptom limited maximal exercise test and a defect on thallium scan with late infilling (one case), and deep anterior $Q$ waves on ECG (three cases).

Measurement of height was taken from the recording at the end of basic training when the mean age was 19.5 years; review of Army statistical tables ${ }^{2}$ shows no increase in height thereafter. Weight was recorded from peri-incident reports, usually at re-admission for definitive investigation and rehabilitation. Relative body weight was calculated using Quetelet's formula ${ }^{3}$ : (weight $(\mathrm{kgs}) /$ height $\left.(\mathrm{cms})^{2} \times 100\right)$, and obesity defined as a relative body weight of 0.28 or more; this corresponds to a $20-25 \%$ increase over the ideal bodye weight according to the criteria of the Metropolitan Life Insurance Company ${ }^{4}$. A positive family history was ${ }^{4}$ recorded when myocardial infarction or angina had든 occurred in the patient's family, his parent's family, or in that of his grandparents. The type and quantity of tobacco consumed was defined numerically in a highe proportion. Blood pressure recordings were taken from? peri-incident reports. Plasma lipids were always estimated from a fasting specimen on a follow-up admission. Similarly glucose tolerance was measured af follow-up on fasting and two hour post prandia: specimens in the main, although 15 were measured on single fasting specimens, and one on urine testing.

\section{Results}

Of 129 cases in which it was recorded $57(44 \%)$ had a family history of myocardial infarction or angina (Table I). The age of onset of symptoms in fathers of index cases was recorded in 28 of 29 cases; nine (32\%) were under 50 years of age.

Anthropomorphic data were available in 94 cases $(57 \%)$; the mean height and weight were 173.3 (SD 6)

Table 1

Family history of Coronary Heart Disease

\begin{tabular}{lr}
\hline No family history & $72(56 \%)$ \\
Father & $29(22 \%)$ \\
Mother & $12(9 \%)$ \\
Both parents & $2(2 \%)$ \\
Siblings & $4(3 \%)$ \\
Others & $10(8 \%)$ \\
\hline
\end{tabular}


centimetres and 81 (SD 12) kilograms respectively, and $44 \%$ were obese (Figure 1 ).

Tobacco habit was recorded in $114(70 \%)$. One hundred and ten $(96 \%)$ were smokers in whom all but five $(85 \%$ of those recorded) smoked cigarettes. In 17 cases the word "smoker" only was used, and in five "heavy smoker". The estimated daily consumption of these cases was 20 and 30 cigarettes respectively, as shown in Figure 2. Five smoked two ounces of shag tobacco each per week in "roll your own" cigarettes, this was taken as equivalent to 20 cigarettes per day. The average number of cigarettes smoked was 28 (SD 13).

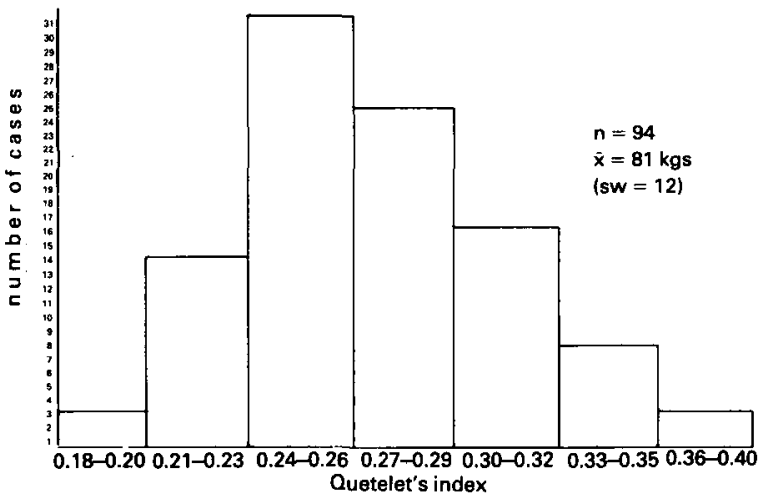

Fig 1 Relative body weight of young soldiers with CHD

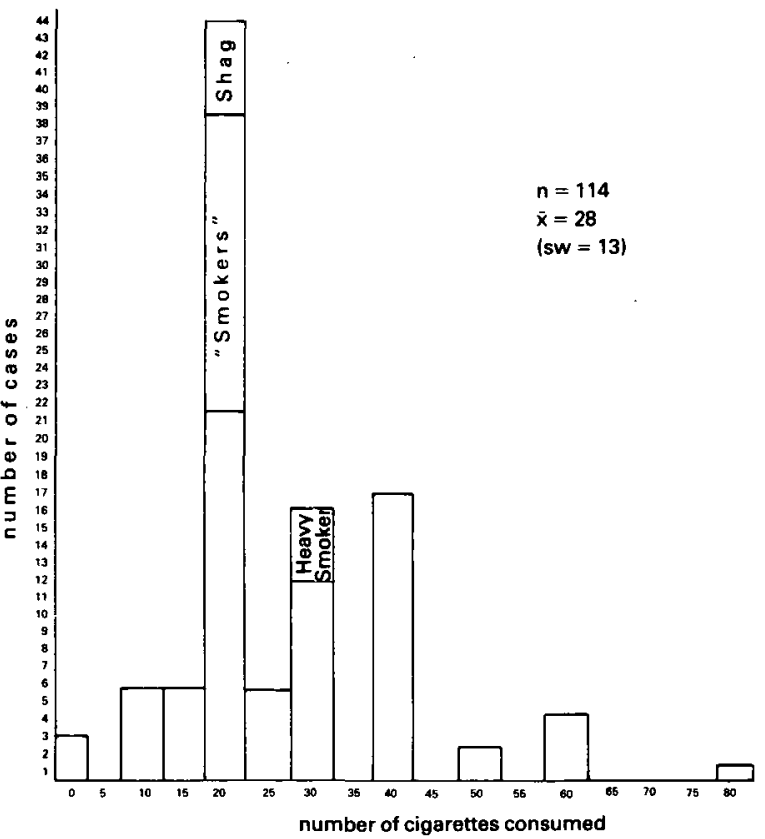

Fig 2 Cigarette consumption in young soldiers with Coronary Heart Disease
Eighty nine per cent of the cigarette smokers smoked 2 or more cigarettes per day, $40 \% 30$ or more and $24 \% 4 \oplus$ or more.

Blood pressure was recorded in 89 cases $(54 \%)$; 18 $(15 \%)$ were greater than $140 / 90$ millimetres of mercury? of which six were greater than $150 / 100$ and four greate than $160 / 110$.

Total serum cholesterol was measured in $93(57 \%$ and the mean level was 7.29 (SD 2.12) millimoles pe $\overline{\overline{5}}$ litre (Figure 3). Taking $7.54 \mathrm{mmol} / 1$ as the upper limit of normal for this age group (30-40 years) there were 28 cases in which it was elevated $(27 \%)$, the mean of these abnormal values being 9.85 (SD 2.17) mmol/1. Higla density lipoprotein cholesterol estimations were carried out in 33 of these cases and the mean value was 1.16 (SL $0.33) \mathrm{mmol} / 1$. The mean of 79 triglyceride estimations: was 2.05 (SD 1.24) $\mathrm{mmol} / 1$. Three of 70 estimations of glucose tolerance were abnormal; none was frankl diabetic.

\section{Discussion}

Tobacco habit was recorded in only $70 \%$ of cases. 강 order to establish that the findings from this proportion are a true reflection of the whole population, let thsconsider the "worst case" situation in which all those? whom there are no data are, in fact, non-smokers. There are then 110 smokers in the population of 164 , giving "worst case" prevalence of $67 \%$. This figure is silit greater than the $60 \%$ prevalence reported in the Britas

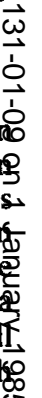

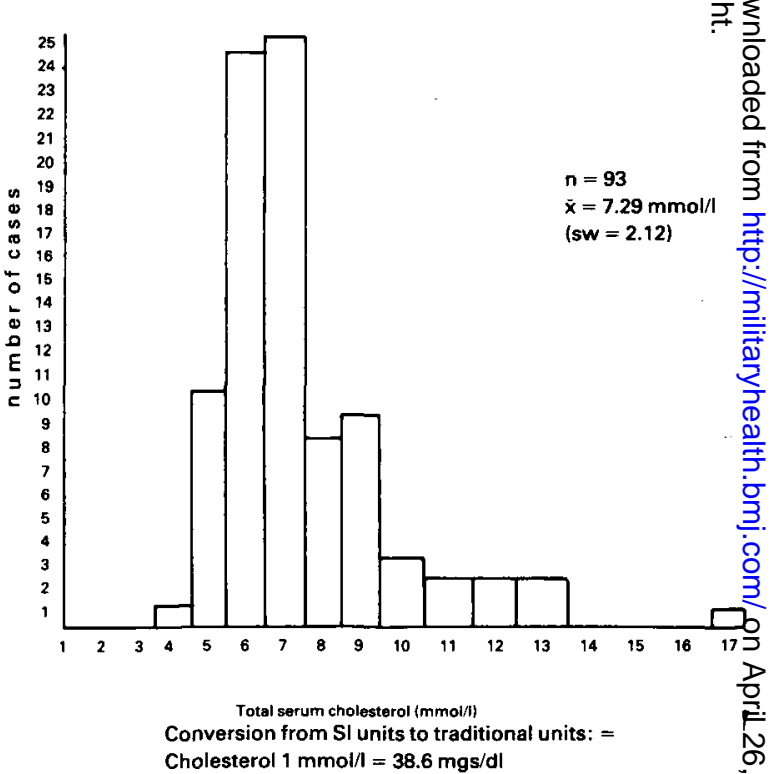

Fig 3 Total serum cholesterol in young soldiers with ㅇ Coronary Heart Disease 
Army by $1980^{5}$, and both are considerably in excess of the 1980 civilian figure of $45 \%{ }^{6}$. The difference is more striking when the quantity smoked is considered. Forty per cent of the 110 smokers consumed 30 or more cigarettes per day. In the worst case all the unknowns smoke less than 30 per day. There are then 44 who smoke 30 or more in a population of 160 smokers, giving a prevalence of $28 \%$. Since in the Army as a whole, the proportion of smokers smoking 30 or more is only $12 \%{ }^{7}$ the inference that heavy smoking is an important risk factor holds good.

Weight measurements were taken in the main from recordings taken six weeks after a coronary event and so might be expected to be a little high as a result of inactivity. Whilst this is likely to bias the comparison with normals, it is probable that other studies on CHD patients would show a similar bias.

Bias might also result from a more honest confession of smoking habit following discovery of CHD than might be expected from routine screening of the healthy.

The Pulheems Administrative Pamphlet (based on the General Household Survey 1962) in which the Army lays down the ideal indices of height and weight recommends a Quetelet's index of 0.23 for the age range $30-40$ years. However a study by Amor on over 3,000 healthy soldiers of similar age in 1975 found a mean index of $0.24^{8}$. British civilian studies on slightly older age groups show indices variously between 0.24 and $0.26^{\Phi, 10,11}$. Thus British soldiers with CHD (mean index 0.27 ) have greater relative body weight than healthy soldiers or healthy civilians.

Of the sample of 114 soldiers with CHD $96 \%$ were smokers, compared with a background prevalence in the Army in 1980 of $60 \%$ and a male civilian prevalence in the same year of $45 \%{ }^{6}$. In the same sample $89 \%$ of cigarette smokers in the study smoked 20 or more per day compared with a $52 \%$ of healthy soldiers ${ }^{7}$ and $23 \%$ of male civilians ${ }^{6}$. The mean total serum cholesterol level in the 93 men studied was $7.29 \mathrm{mmol} / \mathrm{l}$ and $27 \%$ had levels in excess of $7.54 \mathrm{mmol} / \mathrm{l}$. There have been no comprehensive studies of blood lipids in the British Army, but in normal middle aged British civilians, total serum cholesterol varies between 6.0 and $6.6 \mathrm{mmol} /$ $1^{11,12}$. The mean high density lipoprotein cholesterol level in the group of 33 soldiers studied $(1.16 \mathrm{mmol} / \mathrm{l})$, is not importantly different from the range found in normal middle aged male British civilians (1.07-1.22 $\mathrm{mmol} / \mathrm{l})^{12}$. Similarly, the mean triglyceride level of 2.05 $\mathrm{mmol} / \mathrm{l}$ was similar to that found among normal middle aged British male civilians $(1.8 \mathrm{mmol} / \mathrm{l})^{\mathrm{P1}}$.

Very few studies on the risk profile of men under 40 years of age with CHD have been carried out. From Table II it can be seen that the prevalence of abnormal glucose tolerance and of hypertension are much lower in this study than in others (presumably the result of Army medical selection) and a positive family history has ace similar prevalence to most other Western studies. Hypercholesterolaemia appears highly prevalent in $\stackrel{\mathscr{P}}{+}$ young men with CHD compared to the middle aged, but $\square=$ the prevalance in the British Army subjects is similar to that found in young Scandinavians ${ }^{13}$, young $\operatorname{Scots}^{14}$, and

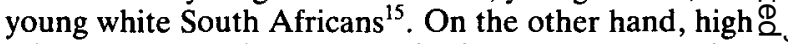
relative body weight and high cigarette consumption appear importantly more prevalent among the soldiers.

Of the parameters studied, high relative body weight, high cigarette consumption, high serum cholesterol and family history are the main risk factors associated with CHD in young soldiers, and the first two are more prevalent than in similar studies on civilians. Levels of high density lipoprotein cholesterol, triglyceride, and

Table II

Risk profiles of subjects under 40 years of age with Coronary Heart Disease

\begin{tabular}{|c|c|c|c|c|c|c|c|}
\hline Present Study & $\begin{array}{l}\text { Present } \\
\text { Study }\end{array}$ & $\begin{array}{c}\text { (19) } \\
\text { Glover }\end{array}$ & $\begin{array}{c}(13) \\
\text { Nitter-Haug }\end{array}$ & $\begin{array}{c}\text { (20) } \\
\text { Bergstrand }\end{array}$ & $\begin{array}{c}\text { (14) } \\
\text { Dolder }\end{array}$ & $\begin{array}{c}\text { (21) } \\
\text { Chinniah }\end{array}$ & $\begin{array}{c}(15) \\
\text { Kennelly }\end{array}$ \\
\hline Number of cases & & 89 & 66 & 24 & 240 & 94 & 100 \\
\hline Total cholesterol (mmol/l) & 7.29 & normal & 8.2 & 7.5 & - & - & 6.75 \\
\hline$\%$ hypercholesterolemic ${ }^{1}$ & 21.5 & 20 & 35 & 60 & 25 & 9 & 17 \\
\hline$\%$ smokers & 96 & 89 & 86 & 92 & 80 & 76 & 85 \\
\hline$\%$ heavy smokers ${ }^{2}$ & 49 & - & - & 50 & 39 & 27 & 33 \\
\hline$\%$ overweight $^{3}$ & 44 & - & 30 & 8 & 19 & 25 & 27 \\
\hline$\%$ with family history & 44 & 48 & 44 & 20 & 25 & 4 & 31 \\
\hline$\%$ hyptertensive & 4 & 21 & 24 & 9 & 15 & 20 & 11 \\
\hline$\%$ glucose intolerance & 4 & - & - & - & 10 & 20 & 7 \\
\hline
\end{tabular}

1. Present study $>9 \mathrm{mmol} / \mathrm{l}$. Glover, not specified. Nitter-Haug $>8.8 \mathrm{mmol} / \mathrm{l}$. Bergstrand $>7.0 \mathrm{mmol} / \mathrm{l}$. Dolder $>7.25 \mathrm{mmol} / \mathrm{l}$. Chinniah $>7.8 \mathrm{mmol} / \mathrm{l}$. Kennelly $\geqslant 7.8 \mathrm{mmol} / \mathrm{l}$.

2. Consuming 25 or more cigarettes per day.

3. $20 \%$ overweight or Quetelet's index $\geqslant 0.28$. 
blood pressure are similar to those among affected civilians, and the low prevalence of glucose intolerance is likely to be due to the Army's invaliding policy for diabetics.

While young soldiers with CHD are markedly more obese than similar civilians the prevalence of obesity in the Army as a whole is slightly lower than among the civilians, although the inference of obesity from high relative body weight is a qualified one in fit and relatively muscular young men. Nevertheless, obesity may cluster among CHD cases through the medium of social drinking; high cigarette consumption and obesity may be associated with heavy beer drinking. Obese soldiers have great difficulty in passing the Basic Fitness Test and are often medically downgraded for both reasons. The net effect is that the soldier is excused exercise and consequently he loses its putative cardioprotective effect.

Review of Table II suggests that young men in general with CHD have a higher prevalence of cigarette smoking and a higher per capita consumption than older men similarly affected. They also appear to have higher total cholesterol levels, perhaps due to the tendency of familial hypercholesterolaemia to present as CHD at an age when $\mathrm{CHD}$ is otherwise uncommon. However, since hypercholesterolaemia is common to all cases of $\mathrm{CHD}$ in young men it cannot be regarded as the explanation for the disproportionately high mortality from CHD among soldiers. It does suggest, however, that screening of recruits for hypercholesterolaemia might be a worthwhile undertaking.

Young soldiers with CHD not only have the highest prevalence of cigarette smoking, but also the highest per capita consumption, and the highest proportion of heavy smokers of all populations that the author has been able to study. Since their smoking habit prior to enlistment is the same as the civilian population from which they derive $^{16}$, and since their adult and lifelong smoking habits are established by the age of 20 years ${ }^{17,18}$, it would seem that the critical phase which determines the soldier's high risk profile is the first few years of Army life. It is at this point that young soldiers are introduced to a population of heavy smokers and can, in many parts of the world, indulge the habit at approximately one quarter of the cost which pertains in the United Kingdom.

Thus the critical difference between the risk profile of soldiers and that of civilians appears to be smoking habit, and this is likely to be the most important factor in explaining why soldiers have a higher mortality from CHD than comparable civilians. Like the case of the Karelian lumberjacks, any beneficial effect from strenuous exercise is swamped by an increase in cigarette consumption.

\section{REFERENCES}

1. LYNCH, P and Oelman, B J. Mortality from coronar heart disease in the British Army compared with the civilian population. Brmed J 1981; 283 : 405-7.

2. Statistical tables on the health of the Army (1974). Armg code no 61443. Ministry of Defence.

3. KHOSLA, T and LowE, C R. Indices of obesity derived from body weight and height. BrJ Prev Soc Med 1967; 2f: 122.

4. Metropolitan Life Insurance Company. Rise in mortality last year. Statistical Bulletin, Metropolitan Life Insuranco Company, 1959; 40: 1 .

5. CRAWFORD, I P and SMITH, R J. Report on the health survey conducted on two Divisions within 1(BR) Corpy Report available from Parkes Professor of Preventive Medicine. Royal Army Medical College, Millbanț. London SW1.

6. Office of Population Censuses and Surveys Monitor GHS5 83/3 1983.

7. CROWDY, J P and SOWDEN, R R. Cigarette smoking and respiratory ill health in British Army. Lancet 1975; $\mathrm{E}$ $1232-4$.

8. AMOR, A F. Preliminary data from a survey of physica' fitness in the Army. (1065-7910) BR65413, 1975 APRE ADV-REP-60. Ministry of Defence.

9. JARRETT, R J, SHIPLEY, M J and Rose, G. Weight $\mathrm{J}_{\mathrm{and}}$ mortality in the Whitehall study. Br Med J 1982; क्षृ 535-7.

10. ROBERTSON, F W, et al. Coronary heart disease in: $\mathbf{N E}$ Scotland. A study of genetic and environmental variatpon

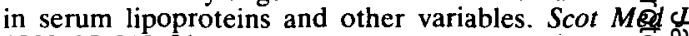
1980; 25: 212-21

11. SEDGEWICK, A W, et al. Long term effects of phy training programme on risk factors for coronary heap disease in otherwise sedentary men. Br Med J 1980; 7-10.

12. ShAPER, A G, et al. British regional heart study; carộifo vascular risk factors in midddle aged men in 24 to Brmed J 1981; 283: 179-86.

13. NitTer-Hauge, $S$, et al. Angiographic and risk faotó characteristics of subjects with early onset ischemic heaf disease. Br Heart J 1981; 46: 325-30.

14. DOLDER, M A and OlIver, M F. Myocardial infarction young men: study of risk factors in nine countrie@ Br Heart J 1975; 37: 493-503.

15. Kenelly, B M. Aetiology and risk factors in yourf patients with recent acute myocardial infarction? S A Med J 1982; 61: 503-7.

16. Richards, H J A and CROwDY, J P. Smoking habits young soldiers. Br J Prev Soc Med 1961; 15: 84-8.

17. Crowdy, J P, Lewthwaite, C J and Sowden, $R$ Smoking: the changing habits of male adolescents. comparison of 3 generations of young soldiers. J R Arm Med Corps 1975 ; 121: 126-31.

18. TODD, G F. Statistics of Smoking in the United Kingdom Research paper No 1, 6th edition 1972. Tobacc焉 Research Council.

19. Glover, MU, et al. Myocardial infarction before age 38 risk factors and arteriographic analysis. Am J Cardto 1982; 49: 1600-3.

20. BREGSTRAND, $\dot{R}$, et al. Myocardial infarction amon young men below age 40 . Br heart $J 1978 ; 40$ : 783-8.

21. Chinniah, D and Yavagal, S T. Prospective study of 100 young myocardial infarction patients from South India. J A ssoc Phys Ind 1979; 27: 479-85. 